\title{
Home range of newborn blacktip reef sharks (Carcharhinus melanopterus), as estimated using mark-recapture and acoustic telemetry
}

\author{
Bouyoucos lan A. 1, 2, * , Romain Martin ${ }^{2}$, Azoulai Lorine 2, Eustache Kim 2, 3, Mourier Johann 2, 4, 5,
} Rummer Jodie L. ${ }^{1}$, Planes Serge ${ }^{2,5}$

\begin{abstract}
${ }^{1}$ Australian Research Council Centre of Excellence for Coral Reef Studies, James Cook University, Townsville, QLD, 4811, Australia

2 PSL Research University, EPHE-UPVD-CNRS, USR 3278 CRIOBE, Université de Perpignan, 58

Avenue Paul Alduy, 66860, Perpignan Cedex, France

${ }^{3}$ Institute for Biodiversity and Ecosystem Dynamics, University of Amsterdam, 1090 GE, Amsterdam,

The Netherlands

4 UMR MARBEC (IRD, Ifremer, University of Montpellier, CNRS), 34000, Sète, France

${ }^{5}$ Laboratoire D'Excellence “CORAIL," EPHE, PSL Research University, UPVD, CNRS, USR 3278

CRIOBE, Papetoai, Moorea, French Polynesia
\end{abstract}

*Corresponding author : Ian A. Bouyoucos, email address : ian.bouyoucos@my.jcu.edu.au

\begin{abstract}
:
Sharks play important functional roles in coral reef ecosystems. Studying reef shark populations' spatial ecology also contributes important data for effective conservation planning. The purpose of this study was to define the home range of neonatal blacktip reef sharks (Carcharhinus melanopterus) around Moorea, French Polynesia, and compare estimates using both mark-recapture surveys and active acoustic telemetry. Mark-recapture surveys produced a minimum convex polygon (MCP) of $0.07 \mathrm{~km} 2$ that was significantly larger than the MCP derived from acoustic telemetry $(0.02 \mathrm{~km} 2)$. Acoustic telemetry produced 50 and $95 \%$ kernel utilization densities that were smaller $(0.02 \mathrm{~km} 2)$ and larger $(0.14 \mathrm{~km} 2)$ than home range estimates from mark-recapture surveys, respectively. Home range estimates from this study are the smallest that have been documented for neonatal blacktip reef sharks, possibly owing to the study sites' proximity to deep channels. Mark-recapture and active acoustic telemetry are complementary approaches worthy of consideration where passive telemetry is impractical
\end{abstract}

Keywords : Elasmobranch, French Polynesia, Kernel utilization density, Marine protected area, Minimum convex polygon, Shark nursery area 


\section{Introduction}

As mesopredators and apex predators, reef sharks play significant functional roles in coral reef ecosystems by exerting top-down control on lower trophic levels (e.g., consumption, fear effects; Roff et al. 2016). Individual sharks can be highly resident (Chin et al. 2016; Mourier et al. 2016) and rely on adjacent, coastal habitats as nursery areas (Heupel et al. 2018). Maintaining healthy reef shark populations has quantifiable benefits for coral reef ecosystem health (Ruppert et al. 2013; Williams et al. 2018). Therefore, identifying key habitats for reef shark populations and describing their use will contribute to more effective conservation planning with the potential for coral reef ecosystem benefits.

An animal's home range represents the area it uses for routine activity over various temporal scales. Exploring an animal's home range offers insight into species' spatial ecology and provides critical information for conservation planning (Oh et al. 2017a). Estimates of home range are typically quantified when exploring habitat use by sharks (Morrissey and Gruber 1993), and this is usually investigated via passive acoustic telemetry (Heupel et al. 2004). However, structurally complex coral reefs or shallow sandflats where reef sharks are observed can attenuate acoustic signals and reduce the efficacy of acoustic telemetry arrays (Heupel et al. 2006). Active acoustic telemetry techniques can overcome signal issues of passive arrays by generating short-term tracks (hours-to-days) of individuals that are closely followed (e.g., by boat or kayak; George et al. 2019). Where acoustic telemetry techniques are not possible, alternative methods for estimating home range, such as mark-recapture surveys, should be considered.

The purpose of this study was to determine habitat use of reef shark neonates within a barrier reef-fringed lagoon. Our first study objective was to compare the home range of neonatal blacktip reef sharks (Carcharhinus melanopterus) within the lagoon surrounding the island of Moorea, French Polynesia as estimated using mark-recapture surveys and acoustic telemetry. By validating an alternative approach to characterizing home range, we hope to offer a tested tool for use in habitats where conventional acoustic telemetry techniques are not viable. Our second objective was to observe whether 
neonates' home range is constrained by deeper habitats such as a dredged boating channel bordering the study site, to suggest whether human action could artificially affect home range. This study has local significance to planning Moorea's marine protected areas (MPAs) and global significance to understanding consequences of habitat loss on the spatial ecology of a coral reef predator.

\section{Materials and methods}

\section{Study site and animals}

Research was approved by the Ministère de la Promotion des Langues, de la Culture, de la Communication, et de l'Environnement (Arrêté n9524) of French Polynesia. Neonates were sampled from Tepee, a potential shark nursery area $\left(17^{\circ} 29^{\prime} 22^{\prime} \mathrm{S}, 149^{\circ} 54^{\prime} 15^{\prime \prime} \mathrm{W}\right)$, and Tiki $\left(17^{\circ} 31^{\prime} 7^{\prime}\right.$ S, $\left.149^{\circ} 54^{\prime} 45^{\prime \prime} \mathrm{W}\right)$. The total area of Tepee, the main study site, is $0.3 \mathrm{~km}^{2}$ and is delineated by natural and dredged boating channels (Figure 1); the artificial channel accounts for $11 \%$ of the area of Tepee. Both sites are shallow ( $50 \mathrm{~cm}$ depth), comprising 56-59\% homogenous coral and sand substrate, 19-34\% coral cover, and seasonal water temperatures ranging from $25^{\circ} \mathrm{C}$ (winter) to $30^{\circ} \mathrm{C}$ (summer). There is a stingray (Pateobatis fai) provisioning site within Tepee that is associated with high adult blacktip reef shark abundance (Kiszka et al. 2016). Both Tepee and Tiki are contained within Moorea's MPA network.

\section{Mark-recapture survey}

Home range of sharks at Tepee was first estimated via mark-recapture survey. Sharks were captured using a gill-net ( $35 \mathrm{~m}$ length by $1.5 \mathrm{~m}$ depth; $5 \mathrm{~cm}$ mesh size) set perpendicular to shore from February to May 2012. Six fishing locations were selected that were approximately 200-600 m apart, dividing the Tepee area into five sections (Figure 1). An initial site (T1) was fished heavily at the start of the study to mark animals for recapture. All other sites were then fished haphazardly, at least three times, to observe how far sharks could be recaptured from T1. Home range was quantified using minimum convex polygons (MCPs, in $\mathrm{km}^{2}$ ). Conventional MCPs could not be derived because mark-recapture yielded two locations per individual. Instead, MCPs were quantified as the area in Tepee between capture 
locations that was bound by the shoreline and channels, based on the a priori assumption that sharks did not swim into deeper water. Analyses were conducted using the Environment for Visualizing Images software (ENVI 4.8, Harris Geospatial Solutions, Inc., Broomfield, CO, USA).

\section{Acoustic telemetry}

For telemetry surveys, sharks were attracted to gill-nets with bait and captured from Tepee at dawn (04:00-07:00) from February to May 2013. Acoustic transmitters (V8 coded transmitter, Vemco, Bedford, Nova Scotia, Canada) were surgically implanted in the body cavity of neonatal sharks while they were held in tonic immobility (Kessel et al. 2015). Transmitters operated at $69 \mathrm{kHz}$ (160-day battery life), transmitted signals every $16 \mathrm{~s}$ during the initial $72 \mathrm{~h}$ (then every $70 \mathrm{~s})$, and weighed $0.9 \mathrm{~g}$ in water $(<$ $0.1 \%$ mass of a $1.0 \mathrm{~kg}$ shark). Surgeries only lasted several minutes, and sharks were retained for at least five minutes following surgery to verify signal detection and ensure animals were in good condition for release. Sharks were then tracked for $24 \mathrm{~h}$ immediately following tagging using a kayak (Meyer and Holland 2001). Attempts were also made, $72 \mathrm{~h}$ post-tagging, to track sharks for an additional $12 \mathrm{~h}$. Acoustic signals were detected with a VH165 omnidirectional hydrophone and VR100 receiver (Vemco, Bedford, Nova Scotia, Canada). Signals could be detected up to $50 \mathrm{~m}$ in $>50 \mathrm{~cm}$ of water over sand substrate; coral heads, strong currents, and rain reduced signal detection down to $2.0 \mathrm{~m}$. Sharks were also acoustically tracked on the island's west coast at Tiki to supplement low sample sizes from Tepee. Minimum convex polygons and core (50\%) and extent (95\%) kernel utilization densities (KUD, $\mathrm{km}^{2}$ ) were estimated to quantify home range in Tepee and Tiki using the "adehabitatHR" package in R (Calenge 2006). After describing sharks' home range, we tested the hypothesis that MCP, as calculated by mark-recapture and acoustic telemetry, would not differ. Comparisons between the two methods were made using a Welch two-sample $t$-test and only for sharks from Tepee. The type-I error rate was $\alpha=0.05$, and analyses were conducted in R (R Core Team 2018). 


\section{Results and discussion}

Blacktip reef sharks' home range could be estimated using both methods (Table 1). Home range for mark-recapture was estimated from only seven of 35 sharks $(\mathrm{TL}=62.5 \pm 4.2 \mathrm{~cm}$; mean $\pm \mathrm{SD})$ that were recaptured at Tepee at a site other than T1 after 10-45 days at liberty. Three sharks were caught between sites $\mathrm{T} 1$ and $\mathrm{T} 4\left(\mathrm{MCP}=0.107 \mathrm{~km}^{2}\right)$ and four sharks were caught between fishing sites $\mathrm{T} 1$ and $\mathrm{T} 3$ $\left(\mathrm{MCP}=0.046 \mathrm{~km}^{2} ;\right.$ Figure 1). Active tracking of six sharks - four of seven from Tepee and two from Tiki (total length, $\mathrm{TL}=65.1 \pm 4.3 \mathrm{~cm}$ ) - yielded $12-100$ detections over at least 72 hours. Core (50\% KUD) habitat use was $0.024 \pm 0.016 \mathrm{~km}^{2}$ and extent (95\% KUD) habitat use was $0.143 \pm 0.142 \mathrm{~km}^{2}$. Neonates at both sites remained in shallow areas with coral cover, avoiding deep channels and exposed sandflats. Previous studies suggest that neonatal blacktip reef sharks appear to prefer shallow, sheltered habitats (Oh et al. 2017b; George et al. 2019). Indeed, this is a possible predator avoidance strategy, especially because there are high densities of adult blacktip reef sharks near a stingray provisioning site at Tepee (Kiszka et al. 2016). Alternatively, neonates may engage in bold, exploratory behaviors, as one of the four sharks tracked at Tepee crossed the artificial boating channel to the east and spent the night swimming over sand substrate on the edge of this channel (Figure 2).

Mark-recapture surveys estimated larger home ranges than acoustic telemetry for sharks at Tepee. Mean MCP from mark-recapture surveys was significantly higher than mean MCP from acoustic telemetry $\left(0.072 \pm 0.012 \mathrm{~km}^{2} \mathrm{SEM}\right.$ and $0.017 \pm 0.005 \mathrm{~km}^{2} \mathrm{SEM}$, respectively; $\left.t=4.03, \mathrm{df}=8, p=0.003\right)$. Acoustically tracked sharks did not swim west of T3. It is unclear, however, whether mark-recapture overestimated MCP, or if acoustic telemetry underestimated MCP. One shark's 95\% KUD was greater than the area of Tepee (Table 1); although, no shark was tracked outside of the MPA containing Tepee. Mark-recapture did not allow us to estimate KUDs; although, this approach could also be used to calculate the maximum linear dimension metric (Papastamatiou et al. 2009). Further, MCP from markrecapture will be influenced by the distance between nets (i.e., 200-600 m) and barriers (e.g., coastline, channels). For instance, our a priori assumption of deep-water barriers may have led to underestimation; 
indeed, one shark was tracked outside the assumed area of Tepee. Further, animals' time-at-liberty (10-45 days for mark-recapture vs. 3 days for acoustic telemetry) could affect comparisons of MCP because blacktip reef sharks increase their home range as they grow (Oh et al. 2017b; Schlaff et al. 2017).

Neonates tracked in this study exhibited much smaller home ranges than blacktip reef shark neonates from other populations (Papastamatiou et al. 2009; Chin et al. 2016; Oh et al. 2017b). Home ranges of blacktip reef sharks $(\mathrm{TL}=100.0 \pm 17.0 \mathrm{~cm})$ at Palmyra Atoll were actively monitored for 4-72 hours and had 95\% KUDs of $0.5 \pm 0.2 \mathrm{~km}^{2}$ (Papastamatiou et al. 2009). Differences in home ranges between individuals monitored in this study and the population at Palmyra, which were tracked over similar durations, could reflect differences in habitat availability between high island narrow lagoon and atoll systems. Neonates and juveniles $(\mathrm{TL}=73.2 \pm 10.5 \mathrm{~cm})$ tracked passively in Cleveland Bay, Australia over 666-779 days had 50\% and 95\% KUDs of 3.3 and $19.4 \mathrm{~km}^{2}$, respectively (Chin et al. 2016), and neonates $(\mathrm{TL}=63.9 \pm 16.7 \mathrm{~cm})$ from Mangrove Bay, Australia that were passively monitored from 2-407 days and had 50\% and 95\% KUDs of $1.6 \pm 2.0 \mathrm{~km}^{2}$ and $11.2 \pm 12.5 \mathrm{~km}^{2}$, respectively (Oh et al. 2017b). Here, it is possible that ontogenetic effects on home range, where sharks increase home range with size, explain the differences observed between individuals monitored for our study and the Australian populations in addition to differences in habitat availability. Indeed, proximity to deep water and abundant predators and ontogenetic stage (i.e., neonate) of individuals monitored in this study may explain the very small home ranges observed for blacktip reef sharks around Moorea.

In conclusion, our study provides preliminary insight into habitat use of reef shark neonates within Moorea's barrier reef-fringed lagoon. In fulfilling our first objective, we report the smallest home range estimates for neonatal blacktip reef sharks to date and demonstrate that active acoustic telemetry and mark-recapture surveys yielded different, but complementary results. As such, we recommend a combination of these approaches for comprehensive estimation of home range where conventional passive acoustic telemetry is impractical. Regarding our second objective, individual sharks were actively tracked almost exclusively in sheltered habitats with coral cover, demonstrating avoidance of boating 
channels that may restrict home ranges. Small home ranges and nearshore distributions may

disproportionately expose animals, such as neonatal blacktip reef sharks, to increased intra-specific competition over limited resources and anthropogenic disturbances, including noise pollution from boats or provisioning of larger sharks. Home range estimates of blacktip reef sharks derived from this study should be considered in future conservation planning in French Polynesia.

Acknowledgements The authors wish to thank Elodie Raimondi and staff at the CRIOBE for support during the study. Research was funded by the Laboratoire d'Excellence CORAIL, the Station d'Ecologie Expérimentale of the CRIOBE, and the French Ministère de l'Environnement. IA Bouyoucos was supported by a James Cook University Postgraduate Research Scholarship.

Conflict of interest On behalf of all authors, the corresponding author states that there is no conflict of interest.

\section{References}

Calenge C (2006) The package adehabitat for the R software: a tool for the analysis of space and habitat use by animals. Ecol Modell 197:516-519

Chin A, Heupel M, Simpfendorfer C, Tobin A (2016) Population organisation in reef sharks: new variations in coastal habitat use by mobile marine predators. Mar Ecol Prog Ser 544:197-211

George L, Martins A, Heupel M, Simpfendorfer C (2019) Fine-scale movements of juvenile blacktip reef sharks Carcharhinus melanopterus in a shallow nearshore nursery. Mar Ecol Prog Ser 623:85-97

Heupel MR, Simpfendorfer C, Hueter RE (2004) Estimation of shark home ranges using passive monitoring techniques. Environ Biol Fishes 71:135-142

Heupel MR, Semmens JM, Hobday AJ (2006) Automated acoustic tracking of aquatic animals: scales, design and deployment of listening station arrays. Mar Freshw Res 57:1-13

Heupel MR, Kanno S, Martins APB, Simpfendorfer CA (2018) Advances in understanding the roles and benefits of nursery areas for elasmobranch populations. Mar Freshw Res

Kessel ST, Hussey NE, MacLatchey D (2015) Tonic immobility as an anaesthetic for elasmobranchs during surgical implantation procedures. Can J Fish Aquat Sci 72:1287-1291

Kiszka J, Mourier J, Gastrich K, Heithaus M (2016) Using unmanned aerial vehicles (UAVs) to investigate shark and ray densities in a shallow coral lagoon. Mar Ecol Prog Ser 560:237-242

Meyer CG, Holland KN (2001) A kayak method for tracking fish in very shallow habitats. In: Sibert J.R., Nielsen J.L. (eds) Methods and Technologies in Fish Biology and Fisheries. Springer, Dordrecht, pp 
Morrissey JF, Gruber SH (1993) Home range of juvenile lemon sharks, Negaprion brevirostris. Copeia 1993:425

Mourier J, Maynard J, Parravicini V, Ballesta L, Clua E, Domeier ML, Planes S (2016) Extreme inverted trophic pyramid of reef sharks supported by spawning groupers. Curr Biol 26:2011-2016

Oh BZL, Sequeira AMM, Meekan MG, Ruppert JLW, Meeuwig JJ (2017a) Predicting occurrence of juvenile shark habitat to improve conservation planning. Conserv Biol 31:635-645

Oh BZL, Thums M, Babcock RC, Meeuwig JJ, Pillans RD, Speed C, Meekan MG (2017b) Contrasting patterns of residency and space use of coastal sharks within a communal shark nursery. Mar Freshw Res 68:1501

Papastamatiou YP, Lowe CG, Caselle JE, Friedlander AM (2009) Scale-dependent effects of habitat on movements and path structure of reef sharks at a predator-dominated atoll. Ecology 90:996-1008

R Core Team (2018) R: A language and environment for statistical computing.

Roff G, Doropoulos C, Rogers A, Bozec YM, Krueck NC, Aurellado E, Priest M, Birrell C, Mumby PJ (2016) The ecological role of sharks on coral reefs. Trends Ecol Evol 31:395-407

Ruppert JLW, Travers MJ, Smith LL, Fortin M-J, Meekan MG (2013) Caught in the middle: Combined impacts of shark removal and coral loss on the fish communities of coral reefs. PLoS One 8:e74648

Schlaff AM, Heupel MR, Udyawer V, Simpfendorfer CA (2017) Biological and environmental effects on activity space of a common reef shark on an inshore reef. Mar Ecol Prog Ser 571:169-181

Williams JJ, Papastamatiou YP, Caselle JE, Bradley D, Jacoby DMP (2018) Mobile marine predators: an understudied source of nutrients to coral reefs in an unfished atoll. Proc R Soc B Biol Sci 285:20172456

\section{Table}

Table 1 Home range estimates for blacktip reef sharks (Carcharhinus melanopterus) estimated with two methods

\begin{tabular}{cccccc} 
Site & Shark ID & Method & $\begin{array}{c}\text { Minimum convex } \\
\text { polygon }\left(\mathrm{km}^{2}\right)\end{array}$ & $\begin{array}{c}50 \% \text { Kernel } \\
\text { utilization density } \\
\left(\mathrm{km}^{2}\right)\end{array}$ & $\begin{array}{c}95 \% \text { Kernel } \\
\text { utilization density } \\
\left(\mathrm{km}^{2}\right)\end{array}$ \\
\hline Tepee & CmTe14 & Mark-recapture & 0.046 & - & - \\
Tepee & CmTe15 & Mark-recapture & 0.046 & - & - \\
Tepee & CmTe16 & Mark-recapture & 0.046 & - & - \\
Tepee & CmTe17 & Mark-recapture & 0.046 & - & - \\
Tepee & CmTe9 & Mark-recapture & 0.107 & - & - \\
Tepee & CmTe13 & Mark-recapture & 0.107 & - & - \\
Tepee & CmTe29 & $\begin{array}{c}\text { Mark-recapture } \\
\text { Acoustic }\end{array}$ & 0.107 & - & 0.103 \\
Tepee & 8263 & $\begin{array}{c}\text { telemetry } \\
\text { Acoustic }\end{array}$ & 0.017 & 0.024 & 0.416 \\
Tepee & 8265 & $\begin{array}{c}\text { telemetry } \\
\end{array}$ & 0.024 & 0.051 &
\end{tabular}




\begin{tabular}{|c|c|c|c|c|c|}
\hline Tepee & 8267 & $\begin{array}{l}\text { Acoustic } \\
\text { telemetry }\end{array}$ & 0.026 & 0.029 & 0.133 \\
\hline Tepee & 8270 & $\begin{array}{l}\text { Acoustic } \\
\text { telemetry }\end{array}$ & 0.001 & 0.001 & 0.002 \\
\hline Tiki & 8262 & $\begin{array}{l}\text { Acoustic } \\
\text { telemetry }\end{array}$ & 0.001 & 0.022 & 0.128 \\
\hline Tiki & 8264 & $\begin{array}{l}\text { Acoustic } \\
\text { telemetry }\end{array}$ & 0.009 & 0.017 & 0.072 \\
\hline
\end{tabular}




\section{Figure legends}

Fig. 1 Study site (Moorea, French Polynesia). Tepee is a potential shark nursery area for blacktip reef sharks (Carcharhinus melanopterus) that is delineated by a natural channel to the north and a dredged boating channel to the east. The site has an area of $0.3 \mathrm{~km}^{2}$ as delineated by the dashed black line. Lines perpendicular to shore (T1-6) denote fishing sites where sharks were collected with gill-nets. Two polygons between $\mathrm{T} 1$ and $\mathrm{T} 3$ and $\mathrm{T} 1$ and $\mathrm{T} 4$ represent the home range of sharks captured at $\mathrm{T} 1$ that were recaptured at $\mathrm{T} 3$ and $\mathrm{T} 4$, respectively

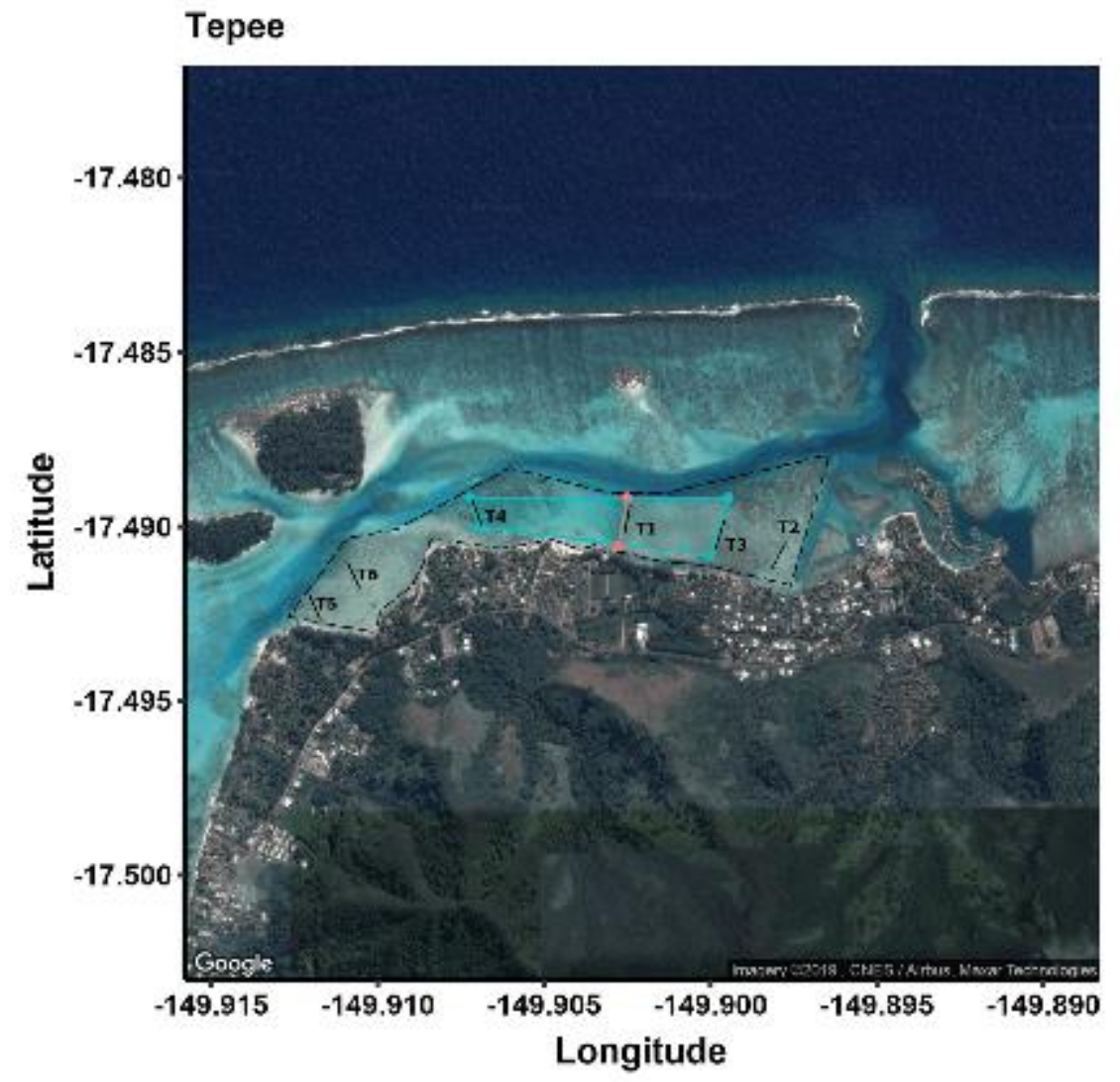

Fig. 2 Detections of blacktip reef sharks (Carcharhinus melanopterus) actively tracked with acoustic telemetry around Moorea Island, French Polynesia. Different colors denote the home range (i.e., minimum convex polygon) of different individuals at Tepee $(A ; n=4)$ and Tiki $(B ; n=2)$. 
(a) Tepee

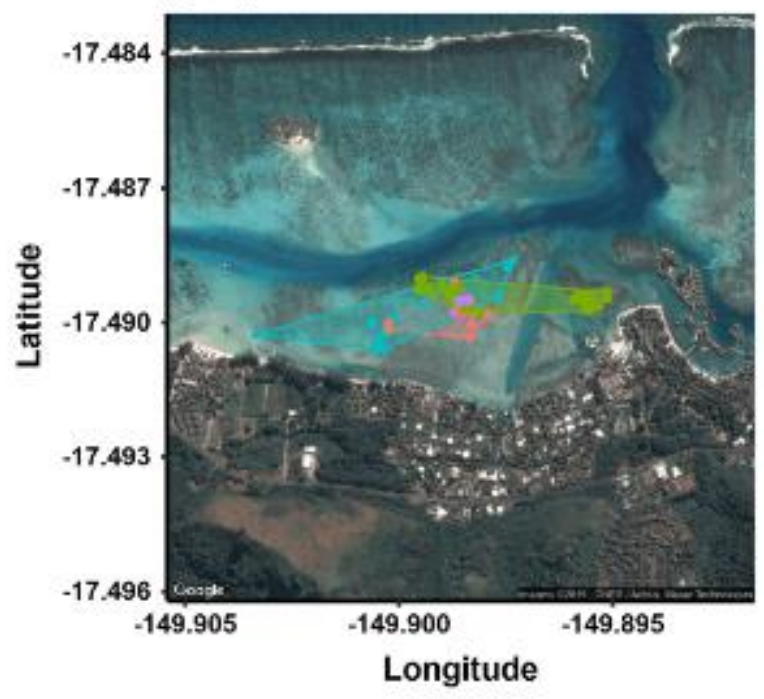

(b) Tiki

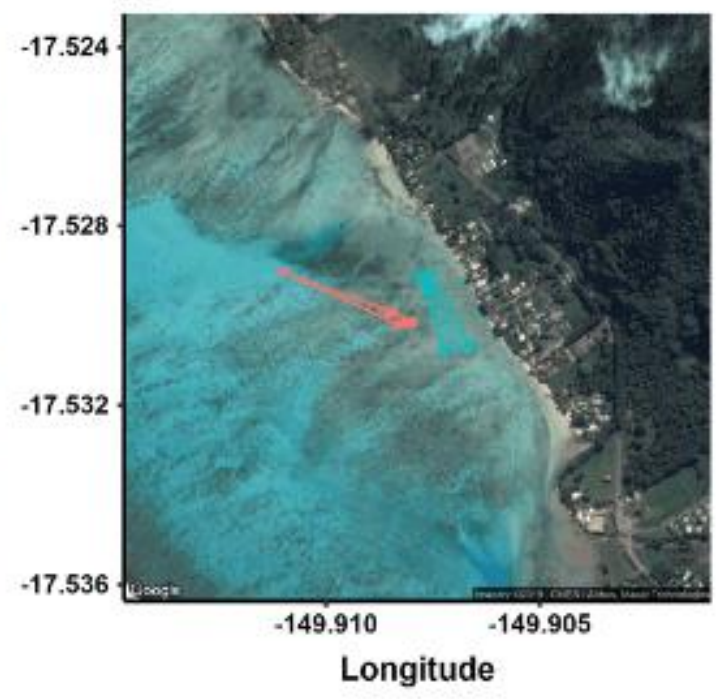

